\title{
Comparison of the effects of stability exercise and balance exercise on muscle activity in female patients with chronic low back pain
}

\author{
Dae-Hyun Kim, Tae-Ho Kim* \\ Department of Physical Therapy, College of Rehabilitation Science, Daegu University, Gyeongsan, Korea
}

Stability exercise (SE) and balance exercise (BE) are generally-applied clinical interventions for back pain. For a proper clinical application, it is necessary to characterize and compare the effects of $S E$ and $B E$ on low back pain (LBP). The purpose of this study was to compare the effects of $S E$ and $B E$ on the activity of trunk muscles in women with chronic LBP. Women with chronic LBP $(n=30)$ who volunteered for this study were randomly divided into two exercise groups of 15 participants. We obtained pre- and postintervention data through application of the visual analogue scale (VAS), Oswestry Disability Index (ODI), and electromyography (EMG). While post-intervention EMG showed decreased activity of the external oblique (EO) in the SE group, the EMG results in the $\mathrm{BE}$ group showed increased $\mathrm{E} 0$ activity $(P<0.05)$. Both groups had increased muscle activity of the erector spinae $(P<0.05)$. Both groups showed significant reductions on the VAS and ODI $(P<0.05)$. Both $S E$ and $B E$ were effective in reducing pain in the study participants. The decrease in EO muscle activity in the SE group seems to be due to the SE inducing cocontraction and distributing the role of the $\mathrm{EO}$ to other muscles. In contrast, EO muscle activity was increased in the $\mathrm{BE}$ group. It appears that the $\mathrm{EO}$ is important in maintaining the center of gravity and base of support during BE. The role of EO seems to maintain trunk stability as it increases muscle activity of $\mathrm{EO}$.

Keywords: Low back pain, Trunk muscle activity, Electromyography, Stability exercise, Balance exercise, Female patients

\section{INTRODUCTION}

Low back pain (LBP) is the most common musculoskeletal complaint in today's societies, with up to $60 \%$ lifetime prevalence; about $40 \%$ of people have had LBP during the last 12 months, with a point prevalence of $12 \%-20 \%$ (Hoy et al., 2012). A minority of these are repeated recurrences with persistent symptoms (Meziat Filho et al., 2009). In the acute phase of back pain, symptoms disappear after appropriate treatment, but the weakness of back muscles due to lack of exercise in daily life and posture instability due to improper posture leads to instability of the spine, resulting in chronic back pain and long-term disability (Hirasawa et al., 2007). Muscle impairment and motor control dysfunction appear to be strongly associated with chronic and recurrent LBP (Silfies et al., 2009). Back pain is most common among men and women between the ages of 30 and 50 ( $\mathrm{Ng}$ et al., 2018), mainly occurring in women after the ages of 40 (Hicks et al., 2005). This is due to a decrease in muscle mass, an increase in osteoporosis, and a high frequency of housework laboring at the waist (Marini et al., 2017). Many previous studies have investigated chronic back pain and have described the main cause of back dysfunction and pain as the weakening of the abdominal muscles (Hodges, 2011). When back pain progresses for months, the movement of the body is restricted and the muscles atrophy. If the condition becomes chronic, the cross-sectional area of the muscle around the vertebral bodies is decreased, leading to deterioration of back pain, secondary damage, and recurrence (Danneels et al., 2001). The available evidence suggests that education alone, back belts, shoe insoles, and ergonomics do not prevent LBP (Steffens et al., 2016). There is evidence that muscle management through exercise is the best
${ }^{*}$ Corresponding author: Tae-Ho Kim (iD https://orcid.org/0000-0001-7939-2139 Department of Physical Therapy, College of Rehabilitation Science, Daegu University, 201 Daegudae-ro, Jillyang-eup, Gyeongsan 38453, Korea Tel: +82-53-850-4354, Fax: +82-53-850-4359, E-mail: hohoho90@naver.com Received: September 6, 2018 / Accepted: November 6, 2018
This is an Open Access article distributed under the terms of the Creative Commons Attribution Non-Commercial License (http://creativecommons.org/licenses/by-nc/4.0/) which permits unrestricted non-commercial use, distribution, and reproduction in any medium, provided the original work is properly cited. 
treatment for back pain.

Stability exercise (SE) has been used for the treatment of patients with chronic back pain because of the advantage of strengthening by inducing coordinated contraction of trunk muscles to restore functional posture and movement control. Therefore, SE is becoming an essential LBP approach (Noormohammadpour et al., 2018). McGill recommended curl-up, side bridge, and bird dog for trunk stability in patients with back pain (McGill and Karpowicz, 2009); Wasser also recommended a step-bystep exercise method (Wasser et al., 2017). These exercises emphasized muscular coordination and cocontraction as well as muscle strength around the trunk.

Patients with chronic back pain are less able to maintain one leg standing posture (Luoto et al., 1998), improvement of strength and improvement of balance should be done together (Frost and Brown, 2016). Sensory-motor training, which stimulates the proprioceptive sensor using unstable surfaces, (Ehrenbrusthoff et al., 2018) is effective to normalize the muscle response pattern by stimulating the deep muscles involved in stability (Silfies, 2009). Low-load local muscle exercise is associated with long-term improvement in feedforward postural adjustments (Tsao et al., 2008). The use of an unstable surface may increase the activation of global and local trunk muscles during bridging exercises in the supine and prone positions (Kang et al., 2012). Individuals with LBP may be better able to recruit the transverse abdominis $(\operatorname{Tr} A)$ during the more complex unstable-based tasks. Clinically, unstable-based therapy can be used to train the neuromuscular system of the deep spinal stabilizers in subjects with LBP (Saliba et al., 2010).

The purpose of this study is to investigate the difference between balance exercise (BE) that can give a proprioceptive stimulus using an unstable support surface, and a SE that induces cocontraction and coordination of muscles during certain functions. There are few studies comparing the therapeutic effects of SE with features that induce coordination and $\mathrm{BE}$ using proprioceptive stimulation on an unstable surface, in female LBP patients. The goal of this study is to compare the therapeutic effects of the two exercise methods.

\section{MATERIALS AND METHODS}

\section{Subjects}

Thirty female patients with chronic LBP and lack of exercise participated in this study. All participants were recruited through local physical therapy clinic's poster advertisements. All subjects were informed of the purpose and methods of this study, and their consent was approved by the Institutional Review Board of Daegu University (1040621-201711-HR-032-002). The participants were selected based on the criteria listed below.

(a) Patients with chronic LBP for more than 12 weeks.

(b) Patients who have relapsed more than three times with LBP.

(c) Patients between the ages of 20 and 60 years.

(d) Patients without back surgery experience.

(e) Patients without spinal deformity, bone fracture, or scoliosis on radiological examination.

(f) Patients without sensory neuropathy, nervous system problems, respiratory system disease, or brace.

(g) Patients without a recent history of other musculoskeletal disorders.

(h) Patients who have not regularly or systematically exercised in their daily lives for the past three years.

\section{Surface EMG recording and data processing}

In this study, to measure the muscle activity of external oblique (EO), internal oblique (IO), and erector spinae (ES) in the participants, we referred to the previous studies and marked with oil pen the electrode attachment area of each muscle. The areas were marked so that the electrodes could be repositioned in the same areas. Participants were prepped for surface electromyography (EMG) electrode placement using standard protocols of shaving and wiping the skin with rubbing alcohol. Disposable pre-gelled EMG $\mathrm{Ag}-\mathrm{AgCl}$ electrodes with a 1.5 -cm center-to-center inter-electrode distance were applied with individual electrodes placed perpendicular to the muscle fiber orientation and electrode pairs placed parallel to the muscle belly over the following 3 muscle groups: $\mathrm{EO}$ (below the rib cage, along a line connecting the inferior costal margin and the contralateral pubic rim) (Ng et al., 1998); IO (1 $\mathrm{cm}$ medial to the anterior superior iliac spine [ASIS] just below a line joining the bilateral ASIS) (Ng et al., 1998); and lumbar portion of the ES (between the midline and lateral aspect of the body at the L1 vertebral level) (Dankaerts et al., 2006). Electrode placements were confirmed with palpation and manual resistance to muscle groups. Unipolar electrodes were used and the distance between the centers of the electrodes was fixed at $1.5 \mathrm{~cm}$. EMG activity was recorded with a $1,500-\mathrm{Hz}$ sampling frequency using a TeleMyo DTS (Noraxon Inc., Scottsdale, AZ, USA). The EMG signal processing was analyzed with Myo-Research Master Edition 1.06 software. EMG signals had bias removed, and were band-pass (cutoff frequency 20-450 Hz) and band-stop (cutoff frequency 59-61 Hz) (Naddaf et al., 2018) filtered to remove 
movement artifact and 60-Hz electrical noise using notch filters. Root mean square processing was performed to quantify the collected EMG signals.

Because the study subjects were limited by pain, the $\%$ maximum voluntary isometric contraction was difficult to measure and the $\%$ reference voluntary contraction (RVC) was measured instead. Prior to instrumentation for motion capture, RVCs for all muscle groups were obtained for EMG normalization purposes (Sundelin and Hagberg, 1989). Participants were positioned prone with knees flexed to 90 degrees and asked to lift their thighs off the surface for three seconds to obtain RVCs for trunk and hip extensors (Dankaerts et al., 2004). RVCs for trunk flexors were obtained with participants lifting bilateral feet approximately $8 \mathrm{~cm}$ off the table for duration of $3 \mathrm{sec}$ from a hook-lying position (Dankaerts et al., 2004). The surface EMG was measured in the kneeling leaning-forward position with the electrodes attached to the trunk. The subjects were held in a kneeling position with both hands holding the sling handle at the ASIS position and tilting forward to angle the shoulder to 90 degrees and keeping it in position for three seconds. The muscle activity of EO, IS, and ES used in this posture was measured, and the RVC was calculated by repeating the measurement three times. Rest time between measurements was given for one minute. One expert performed all measurements. Oswestry Disability Index (ODI) and visual analogue scale (VAS) were measured pre- and posttest. ODI was used to determine the change in lumbar function. VAS was used to determine changes in LBP.

\section{Experimental procedures}

Both groups exercised for 3 days a week, $30 \mathrm{~min}$ a day, for 8 weeks. The SE program is McGill's exercise (curl up, side bridge, and bird dog), and Sahrmann 0-5 level exercise. After 4 weeks, the SE program progressed to a higher level of difficulty.

The BE program was performed with standing, spot walking, and one leg standing using a Pro balance trainer (BOSU, Ashland, $\mathrm{OH}, \mathrm{USA}$ ) and sitting exercise, standing, and one leg standing

Table 1. General characteristics of participants

\begin{tabular}{lccc}
\hline Characteristic & SEG & BEG & $P$-value \\
\hline Gender, female & 15 & 15 & \\
Age $(\mathrm{yr})$ & $22.31 \pm 1.6$ & $22.92 \pm 1.55$ & 0.822 \\
Height $(\mathrm{cm})$ & $166.31 \pm 7.84$ & $166.92 \pm 8.62$ & 0.592 \\
Weight $(\mathrm{kg})$ & $57.15 \pm 9.73$ & $57.15 \pm 8.76$ & 0.362 \\
Body mass index $\left(\mathrm{kg} / \mathrm{m}^{2}\right)$ & $23.20 \pm 2.90$ & $22.72 \pm 1.81$ & 0.754 \\
\hline
\end{tabular}

Values are presented as number or mean \pm standard deviation.

SEG, stability exercise group; BEG, balance exercise group. using a dynamic air cushion (TOGU, Prien-Bachham, Germany). After 4 weeks, the BE program progressed to a higher level of difficulty.

\section{Statistical analyses}

All statistical analyses (gender, age, height, weight, and body mass index) were conducted using IBM SPSS ver. 18.0 (IBM Co., Armonk, NY, USA). Independent $t$-test was used to compare the differences between two groups. The Shapiro-Wilks analyses were used to test normality of all data of the different quintiles. Paired $t$-test was used to compare the muscle activity before and after experiment between groups. Statistical significance $\alpha$ was set at 0.05 .

\section{RESULTS}

There was no significant difference in the general characteristics of the subjects between the two groups $(P>0.05)$ (Table 1). Table 2 shows the results of the EMG activity of each muscle. After the intervention, the EO muscle activity of the SE group decreased from $40.75 \pm 2.76$ (\% RVC) to $36.51 \pm 4.27(P<0.05)$. ES muscle activity of the SE group increased from $64.37 \pm 14.25$ to $81.95 \pm$ $13.33(P<0.05)$. After the intervention, the EO muscle activity of the BE group increased from $42.04 \pm 3.95$ to $42.88 \pm 4.67(P<$

Table 2. The comparison of electromyography in each of the groups at preand post-group

\begin{tabular}{cccccc}
\hline Variable & Pretest & Posttest & Difference value & $t$ & $P$-value \\
\hline EMG-EO & & & & & \\
SEG & $40.75 \pm 2.76$ & $36.51 \pm 2.47$ & $-4.24 \pm 4.45$ & 3.69 & $0.002^{*}$ \\
BEG & $42.04 \pm 3.95$ & $42.88 \pm 4.67$ & $0.84 \pm 1.11$ & -2.93 & $0.011^{*}$ \\
$t$ & -2.47 & & 4.29 & & \\
$P$-value & 0.954 & & 0.001 & & \\
EMG-IO & & & & & \\
SEG & $34.36 \pm 6.85$ & $35.00 \pm 6.53$ & $0.64 \pm 1.19$ & 2.08 & 0.056 \\
BEG & $28.11 \pm 7.66$ & $28.25 \pm 6.75$ & $0.13 \pm 5.09$ & -0.10 & 0.921 \\
$t$ & 1.34 & & -0.38 & & \\
$P$-value & 0.716 & & 0.712 & & \\
EMG-ES & & & & & \\
SEG & $64.37 \pm 14.25$ & $81.95 \pm 13.33$ & $17.59 \pm-8.91$ & 3.46 & $0.004^{*}$ \\
BEG & $50.95 \pm 12.78$ & $59.87 \pm 14.76$ & $19.68 \pm 15.49$ & -2.23 & $0.043^{*}$ \\
$t$ & 3.42 & & -1.34 & & \\
$P$-value & 0.587 & & 0.191 & & \\
\hline
\end{tabular}

Values are presented as mean \pm standard deviation (\% reference voluntary contraction).

EMG, electromyography; EO, external oblique; 10, internal oblique; ES, erector spinae; SEG, stability exercise group; $B E G$, balance exercise group.

${ }^{*}$ Significant difference within group $(P<0.05)$. 
Table 3. The comparison of VAS and ODI in each of the group at pre- and posttest

\begin{tabular}{lccccc}
\hline Group & Pretest & Posttest & Difference value & $z$ & $P$-value \\
\hline SEG-VAS & $4.13 \pm 0.74$ & $1.33 \pm 1.05$ & $-2.8 \pm 1.15$ & -3.432 & $0.001^{*}$ \\
BEG-VAS & $3.93 \pm 0.59$ & $2.33 \pm 1.54$ & $-1.6 \pm 1.4$ & -2.831 & $0.001^{*}$ \\
$U$ & 94.5 & & 60.5 & & \\
$P$-value & 0.027 & & 0.029 & & \\
SEG-ODI & $26.96 \pm 9.85$ & $12.45 \pm 3.12$ & $-14.5 \pm 10.31$ & -3.414 & $0.005^{*}$ \\
BEG-ODI & $26.51 \pm 6.94$ & $15.12 \pm 6.00$ & $-11.4 \pm 4.66$ & -3.417 & $0.001^{*}$ \\
$U$ & 104.5 & & 96.5 & & \\
$P$-value & 0.504 & & 0.512 & & \\
\hline
\end{tabular}

Values are presented as mean \pm standard deviation (score) unless otherwise indeicated.

VAS, visual analogue scale; ODI, Oswestry disability index; SEG, stability exercise group; $\mathrm{BEG}$, balance exercise group.

${ }^{*}$ Significant difference within group $(P<0.05)$.

0.05). ES muscle activity of the BE group increased from $50.95 \pm$ 12.78 to $59.87 \pm 14.76(P<0.05)$. Table 3 shows that there is a significant difference between VAS and ODI before and after intervention in both groups.

\section{DISCUSSION}

The main purpose of this study was to compare the effects of $\mathrm{BE}$ and SE in female patients with chronic LBP. According to the results of VAS and ODI, both exercises seemed to be effective for pain reduction and function enhancement. EMG results showed that EO muscle activity decreased and muscle activity of IO and ES increased in the SE group. This result suggests that other muscles are coordinating in place of the role of EO. This may be interpreted as an effect of appropriate muscle-to-muscle cocontraction resulting in reduced pain and increased function. Even though the EO muscle activity is not high in the posture requiring stability of the trunk, it seems that an appropriate distribution of muscle activity enhanced trunk stability by increasing the muscle activity of $\mathrm{IO}$ and $\mathrm{ES}$.

On the other hand, the activity of EO and ES in the BE group was increased. $\mathrm{EO}$ and $\mathrm{ES}$ were observed to cocontract to maintain the measured posture. It appears that EO is active as a counterforce against the muscle activity of ES. Imai et al. (2010) reported that the $\mathrm{BE}$ on the unstable support surface significantly increased the muscle activity of the EO. The role of EO appears to be important in maintaining the center of gravity within the balancing control base of support during balancing exercise (Ito et al., 2016). The global muscles of the trunk (such as the EO) are concerned with producing and controlling both trunk and pelvis movements
(Richardson et al., 2002). Previous studies suggested that control of the EO muscle is necessary to properly stabilize the spine, maintain optimal alignment and movement, and prevent excessive stress and compensatory motions of the pelvis during movements of the extremities (Ito et al., 2016). It seems that the role of $\mathrm{EO}$ as a trunk stabilizer is emphasized in the stance requiring trunk stability to maintain the upper extremity of the anterior muscle. Among the posterior muscles, the role of ES appears to be to maintain balance on an unstable base like Togu or Bosu.

Both groups showed increased ES muscle activity. This leads us to believe that ES is important in postures that require trunk stability. Participants with reduced pain and increased function were more likely to use ES in a posture that required trunk stability. The superficial group of the ES has an optimal lever arm for lumbar extension. According to Bogduk's study (1992a), 40\%-80\% of the total extension moment is caused by the superficial muscle fibers of the iliocostalis and longissimus attached to the ES aponeurosis. The deep muscle fiber contraction force of ES prevents anterior shear through compression and posterior shear. According to Bogduk (1992a), when the patient is standing upright, the lumbar back extensor causes posterior shear in L1 -4 and anterior shear in L5. This muscle's tension is important for counterbalancing an anterior shear force generated by translation motion of the iliopsoas, such as forward bending. Bogduk (1992b) believed that performing an extension exercise in any posture can cause an injury, especially if there is translational instability in the lumbar spine and compression affects the patient's condition. Hides et al. (2008) reported that patients with multifidus (MF) atrophy need an exercise program designed to restore muscle volume. ES in the posterior as well as the abdominal muscles seem to play a significant role in trunk stability. Clinicians should pay attention not only to the muscles around the abdomen but also to the muscles around the waist in the interventions for back pain.

In summary, SE appears to affect pain control through deep muscle (IO) activation, and $\mathrm{BE}$ appears to affect pain control due to cocontraction of ES and EO. The opposite effect of increasing or decreasing EO seems to be pain control if the distribution of muscle activity is appropriate for trunk stability.

This study has several limitations. It was difficult to measure muscle activity of deep muscles such as $\operatorname{Tr} A$ and MF, which are known to be important for trunk stability, with a surface EMG device. Because it was an experiment using surface EMG, there were difficulties in understanding the relationship between the superficial muscle activation and deep muscle activation of subjects. However, it was difficult to reduce the variability of each 
participant's level of activity during the 8 weeks long intervention. In a future study, we would like to investigate the roles and functions of muscles by measuring the activity, movement, and thickness of deep muscles such as $\operatorname{Tr} A$ and MF using ultrasound.

In conclusion, both groups experienced positive effects of improving lumbar function and improving LBP after 8 weeks of exercise intervention. However, measurements of muscle activity in the two groups showed different results. We recommend SE for patients who need muscle cooperation and $\mathrm{BE}$ for patients who require activation of $\mathrm{EO}$. Considering the difference in individuals' levels of muscle activity, we expect to be able to customize to individual characteristics. Patients with LBP who engage in both $\mathrm{SE}$ and BE may find this to be an effective treatment for back pain. In addition, patients who have difficulty with SE, such as post-surgery patients, elderly people, beginners, and children, may be more effectively treated by applying $\mathrm{BE}$ at the beginning of their exercise therapy.

\section{CONFLICT OF INTEREST}

No potential conflict of interest relevant to this article was reported.

\section{REFERENCES}

Bogduk N, Macintosh JE, Pearcy MJ. A universal model of the lumbar back muscles in the upright position. Spine (Phila Pa 1976) 1992a;17: 897-913.

Bogduk N, Pearcy M, Hadfield G. Anatomy and biomechanics of psoas major. Clin Biomech (Bristol, Avon) 1992b;7:109-119.

Dankaerts W, O'Sullivan P, Burnett A, Straker L. Altered patterns of superficial trunk muscle activation during sitting in nonspecific chronic low back pain patients: importance of subclassification. Spine (Phila Pa 1976) 2006;31:2017-2023.

Dankaerts W, O'Sullivan PB, Burnett AF, Straker LM, Danneels LA. Reliability of EMG measurements for trunk muscles during maximal and sub-maximal voluntary isometric contractions in healthy controls and CLBP patients. J Electromyogr Kinesiol 2004;14:333-342.

Danneels LA, Vanderstraeten GG, Cambier DC, Witvrouw EE, Bourgois J, Dankaerts W, De Cuyper HJ. Effects of three different training modalities on the cross sectional area of the lumbar multifidus muscle in patients with chronic low back pain. Br J Sports Med 2001;35:186-191.

Ehrenbrusthoff K, Ryan CG, Grüneberg C, Martin DJ. A systematic review and meta-analysis of the reliability and validity of sensorimotor measurement instruments in people with chronic low back pain.
Musculoskelet Sci Pract 2018;35:73-83.

Frost LR, Brown SH. Muscle activation timing and balance response in chronic lower back pain patients with associated radiculopathy. Clin Biomech (Bristol, Avon) 2016;32:124-130.

Hicks GE, Fritz JM, Delitto A, McGill SM. Preliminary development of a clinical prediction rule for determining which patients with low back pain will respond to a stabilization exercise program. Arch Phys Med Rehabil 2005;86:1753-1762.

Hides J, Gilmore C, Stanton W, Bohlscheid E. Multifidus size and symmetry among chronic LBP and healthy asymptomatic subjects. Man Ther 2008;13:43-49.

Hirasawa Y, Bashir WA, Smith FW, Magnusson ML, Pope MH, Takahashi K. Postural changes of the dural sac in the lumbar spines of asymptomatic individuals using positional stand-up magnetic resonance imaging. Spine (Phila Pa 1976) 2007;32:E136-140.

Hodges PW. Pain and motor control: from the laboratory to rehabilitation. J Electromyogr Kinesiol 2011;21:220-228.

Hoy D, Bain C, Williams G, March L, Brooks P, Blyth F, Woolf A, Vos T, Buchbinder R. A systematic review of the global prevalence of low back pain. Arthritis Rheum 2012;64:2028-2037.

Imai A, Kaneoka K, Okubo Y, Shiina I, Tatsumura M, Izumi S, Shiraki H. Trunk muscle activity during lumbar stabilization exercises on both a stable and unstable surface. J Orthop Sports Phys Ther 2010;40:369-375.

Ito K, Nonaka K, Ogaya S, Ogi A, Matsunaka C, Horie J. Surface electromyography activity of the rectus abdominis, internal oblique, and external oblique muscles during forced expiration in healthy adults. J Electromyogr Kinesiol 2016;28:76-81.

Kang H, Jung J, Yu J. Comparison of trunk muscle activity during bridging exercises using a sling in patients with low back pain. J Sports Sci Med 2012;11:510-515.

Luoto S, Aalto H, Taimela S, Hurri H, Pyykkö I, Alaranta H. One-footed and externally disturbed two-footed postural control in patients with chronic low back pain and healthy control subjects. A controlled study with follow-up. Spine (Phila Pa 1976) 1998;23:2081-2089.

Marini M, Bendinelli B, Assedi M, Occhini D, Castaldo M, Fabiano J, Petranelli M, Migliolo M, Monaci M, Masala G. Low back pain in healthy postmenopausal women and the effect of physical activity: a secondary analysis in a randomized trial. PLoS One 2017;12:e177370.

McGill SM, Karpowicz A. Exercises for spine stabilization: motion/motor patterns, stability progressions, and clinical technique. Arch Phys Med Rehabil 2009;90:118-126.

Meziat Filho N, Santos S, Rocha RM. Long-term effects of a stabilization exercise therapy for chronic low back pain. Man Ther 2009;14:444-447.

Naddaf E, Milone M, Mauermann ML, Mandrekar J, Litchy WJ. Muscle biopsy and electromyography correlation. Front Neurol 2018;9:839. 
$\mathrm{Ng} J \mathrm{~K}$, Kippers V, Richardson CA. Muscle fibre orientation of abdominal muscles and suggested surface EMG electrode positions. Electromyogr Clin Neurophysiol 1998;38:51-58.

Ng SK, Cicuttini FM, Davis SR, Bell R, Botlero R, Fitzgibbon BM, Urquhart DM. Poor general health and lower levels of vitality are associated with persistent, high-intensity low back pain and disability in community-based women: a prospective cohort study. Maturitas 2018; 113:7-12.

Noormohammadpour P, Kordi M, Mansournia MA, Akbari-Fakhrabadi M, Kordi R. The role of a multi-step core stability exercise program in the treatment of nurses with chronic low back pain: a single-blinded randomized controlled trial. Asian Spine J 2018;12:490-502.

Richardson CA, Snijders CJ, Hides JA, Damen L, Pas MS, Storm J. The relation between the transversus abdominis muscles, sacroiliac joint mechanics, and low back pain. Spine (Phila Pa 1976) 2002;27:399-405.

Saliba SA, Croy T, Guthrie R, Grooms D, Weltman A, Grindstaff TL. Differences in transverse abdominis activation with stable and unstable bridging exercises in individuals with low back pain. N Am J Sports Phys Ther 2010;5:63-73.

Silfies SP, Mehta R, Smith SS, Karduna AR. Differences in feedforward trunk muscle activity in subgroups of patients with mechanical low back pain. Arch Phys Med Rehabil 2009;90:1159-1169.

Steffens D, Maher CG, Pereira LS, Stevens ML, Oliveira VC, Chapple M, Teixeira-Salmela LF, Hancock MJ. Prevention of low back pain: a systematic review and meta-analysis. JAMA Intern Med 2016;176:199-208.

Sundelin G, Hagberg M. The effects of different pause types on neck and shoulder EMG activity during VDU work. Ergonomics 1989;32:527537.

Tsao H, Galea MP, Hodges PW. Reorganization of the motor cortex is associated with postural control deficits in recurrent low back pain. Brain 2008;131(Pt 8):2161-2171.

Wasser JG, Vasilopoulos T, Zdziarski LA, Vincent HK. Exercise benefits for chronic low back pain in overweight and obese individuals. PM R 2017;9:181-192. 